\title{
The Influence of Six-Year Medical Education on Learning Styles in Medical Students at Baskent University
}

\author{
Leyla Aydın'1*, A. Şebnem Ilhan'1, Erhan Kızıltan', Nuray Yazıhan², A. Canan Yazıcı, \\ Nimet Unay Gundogan 1 \\ ${ }^{1}$ Department of Physiology, Medical Faculty, Baskent University, Ankara, Turkey \\ ${ }^{2}$ Department of Pathophysiology, Medical Faculty, Ankara University, Ankara, Turkey \\ ${ }^{3}$ Department of Biostatistics, Medical Faculty, Baskent University, Ankara, Turkey \\ Email: leyla3b@yahoo.com
}

Received 26 March 2015; accepted 20 April 2015; published 27 April 2015

Copyright (C) 2015 by authors and OALib.

This work is licensed under the Creative Commons Attribution International License (CC BY).

http://creativecommons.org/licenses/by/4.0/

(c) (i) Open Access

\section{Abstract}

This study is designed to evaluate the difference between the first year and the sixth year of medical faculty in Baskent University $(n=115)$ by using the Turkish version of the VARK questionnaire. In this survey, VARK questionnaire, which determines a person's sensory modality by describing visual, aural, read/write, and kinesthetic preference, is used. In this study, unimodal model is the most commonly preferred learning model in the first-grade students $(\mathbf{7 5 . 4 \%})$, and aural type is dominant style (31.9\%) changing to the multimodal $(67.4 \%)$ and mostly quad-modal learning style $(17.4 \%)$ in the sixth-year students. There is no gender difference. Learning preferences can differ among students of different faculties. Awareness on the learning preferences of the students facilitates the learning process of the students, and also simplifies the teaching process of the educator in developing appropriate learning methods.

\section{Keywords}

Medical Education, Learning Styles, VARK Questionnaire, Unimodal Learning Model, Multimodal Learning Model

Subject Areas: Education, Pathology, Public Health

\section{Introduction}

Learning style is a term used to refer to the methods of gathering, processing, interpreting, organizing, and

\footnotetext{
${ }^{*}$ Corresponding author.
}

How to cite this paper: Aydın, L., Ilhan, A.Ş., Kızıltan, E., Yazıhan, N., Yazıcı, A.C. and Gundogan, N.U. (2015) The Influence of Six-Year Medical Education on Learning Styles in Medical Students at Baskent University. Open Access Library Journal, 2: e1458. http://dx.doi.org/10.4236/oalib.1101458 
thinking about information. Students have different learning styles, which show up in the classroom in the different ways that students acquire information [1]. These different learning styles have different characteristic strengths and preferences in the ways they take in and process information. In each different styles of learning, students tend to focus on facts, data, and algorithms; others are more comfortable with theories and mathematical models, and some respond strongly to visual forms of information, like pictures, diagrams; others get more from verbal forms [2]. There have been various models developed to explain different learning styles. These models can be divided into four general categories, according to researchers Claxton and Murrell. They divide learning style models into the following: personality models, information-processing models, social-interaction models, and instructional preferences models [3] [4]. These models, for example, can be used to determine if a student is motivated by grades or by interest in material content. The instructional preferences models differentiate students by the way in which they best acquire information [5]. In addition to this, the self-training of individuals, environmental factors and methods applied in educational period all have an impact on the alteration of preferred learning styles [6].

Learning styles are individual characteristics comprising self-specific behaviors which indicate tendencies or preferences associated with learning and show dominance. Accordingly, it has been suggested that the education type and methods might have a direct influence on the establishment of learning styles in medical education [7].

There are many different ways of categorizing learning styles including Index of Learning Styles (ILS), Kolb's model, Jungian model and VARK learning model learning styles [8]-[10]. Neil Fleming's VARK model is one of the most popular representations. Sensory modality preferences are part of learning styles or methods used to process information. In 1987, Fleming developed an inventory which is designed to help students and others learn more about their individual learning preferences. VARK, an acronym for visual, aural, read/write, and kinesthetic preference modalities, is a questionnaire that determines a person's sensory modality preferences. The VARK inventory was developed in an effort to improve faculty development and to help students become better learners. A student may have a preference for one modality or be multimodal; multimodal learners have preferences in more than one model. Students have different learning styles and these can affect how they learn. Physician assistant (PA) programs can potentially improve student learning by administering an intervention such as a learning style inventory. The VARK inventory is one such tool that is easy to use and can give students information on how to maximize their learning. The VARK questionnaire comprises of 16 questions. A different scenario is presented in each question and the preference of the individual is investigated in accordance with these situations. Since individuals may have more than one preference, they may mark more than one option, or else they may leave the question blank. In the questionnaire, each option corresponds to a different learning preference, namely visual (V), aural (A), read-write (R) and kinesthetic (K), presented in different options in each question. The dominantly preferred learning method of the individual is determined by assessment of the responses provided in the questionnaire [11].

Medical education (ME) is in general, a long and compelling process. ME is composed of basic and clinical parts that need different methods of learning tools. This approach suggests that medical students should adapt different learning styles, in addition to comprehension of diverse knowledge. In the present study, we aim to investigate the influence of medical education at Baskent University on the learning styles among medical students, and the VARK learning preferences questionnaire is used to determine the learning styles.

\section{Methods}

\subsection{Population and Sample}

Participants in this study consisted of first-sixth years medical students at Baskent University Faculty of Medicine. Printed form of the questionnaire mailed to the 115 students in the academic year of 2011-2012. All students, $(n=69$ first year, women $=39$, men $=30 ; n=46$ sixth year students women: 30 men: 16), completed the questionnaire. This study was reviewed and approved ethically by the Baskent University Research Evaluation Coordinatorship Social and Human Sciences and Art Research Council.

\subsection{Instrumentation}

The VARK questionnaire developed by Fleming [11] was used to identify one facet of student learning styles: the sensory modality by which they prefer to take in information. The VARK questionnaire is a 13-item, self-re- 
ported, multiple-choice questionnaire that can be completed in 10 - 15 min. The newest version of the VARK questionnaire consists of 16 questions and received from VARK's official web-site. The Turkish version of the VARK also might be found at the same web-site [11] (see the Appendix).

We administered the VARK questionnaire to our first and sixth year's medical students during the 2011-2012 academic years. Students were allowed to choose multiple answers per item to adequately describe their preferred response(s) to the situations presented. The total number of student responses was tallied for each of the four sensory modalities (V, A, R, and $\mathrm{K}$ ) and for all possible combinations of the modalities (e.g., VA, VRK, etc.). The scoring algorithm on the VARK website was then applied to identify each student's modality preferences.

Prediction by students was based on the following four statements:

V learner: uses flowcharts, color coding/highlighting, and recalling information with the aid of diagrams.

A learner: listens to recordings and finds information in lectures easy to recall.

$\mathrm{R}$ learner: makes notes from textbooks and compares those in lectures, rote learning of your notes or from text works best.

K learner: has good recall in practical classes, case studies, or specific real-life examples.

All student data were collected anonymously and identified by a member of staff not involved in the assessment of this cohort. Questionnaires were evaluated on the basis of previously validated scoring instructions and a chart [11].

VARK frequencies were obtained by direct counting. Fisher's Exact and Pearson chi-square tests were used to determine the significance of the differences between proportions. $p<0.05$ was considered statistically significant. SPSS 17.0 statistical package program was used for the analysis of data sets (SPSS Ver. 17.0, SPSS Inc., Chicago, IL, USA).

\section{Results}

The VARK questionnaire is applied to totally 115 students. First year students completed the questionnaire on their lecture attendance and sixth year students completed the VARK assessment in their available times in their clinical training courses. The mean ages were $18.3(17$ - 20) and $24.2(23$ - 27) years in the first and sixth year students respectively.

The most commonly preferred learning model in first year students was the unimodal learning model (75.4\%), with the aural type as the most dominant style (31.9\%) (Figure 1). Among the sixth year students, learning model was found changed to the multimodal learning model (67.4\%) and the most dominant type was determined as the quad-modal learning style (17.4\%) (Figure 2). Comparison of the first and the sixth year students in terms of preferences regarding the unimodal and multimodal learning models revealed dominance of the unimodal learning style among first year students (75.4\%), while the rate of students preferring the unimodal learning model was seen to be significantly decreased in sixth year students $(32.6 \%, p<0.001)$.

The preference for the multimodal learning style was $24.6 \%$ and $67.4 \%$ among the first and sixth grade students respectively $(p<0.001)$ (Figure 3). Comparison of the first and sixth graders in terms of the preference for the multimodal learning model indicated a preference rate of $17.4 \%$ for the bimodal learning model among first graders and a rate of $41.3 \%$ among the sixth graders $(p<0.01)$. Preference for a trimodal learning model was determined as $2.9 \%$ in the first graders, while the corresponding rate among the sixth graders was $8.7 \%$ ( $p>$ 0.05 ). The rates of students preferring a quadmodal learning model was $4.3 \%$ among the first graders and $17.4 \%$ among the sixth graders $(p<0.05)$ (Figure 4).

Furthermore, assessment of all the students in terms of the preference for the quadmodal learning style revealed a rate of $27.3 \%$ in the first graders and $72.7 \%$ in the sixth graders $(p<0.001)$. Among the first and sixth graders preferring a unimodal learning style, the most commonly preferred learning model was the aural type (31.9\% and $15.2 \%$, respectively), followed by the kinesthetic learning type (26.1\% and $13.0 \%$, respectively).

Among the female participants in the first grade, the rate of students preferring an unimodal learning style was determined as $79.5 \%$, while the rate of students preferring a multimodal learning model was $20.5 \%$; the difference was statistically significant $(p<0.001)$. On the other hand, the rate of male participants in the first grade preferring a unimodal learning model was $70 \%$, while the rate of participants preferring a multimodal learning model was $30 \%$, with the difference being statistically significant $(p<0.001)$. The rate of female students preferring a unimodal learning style among first graders was determined as $26.7 \%$ and the rate of participants pre- 


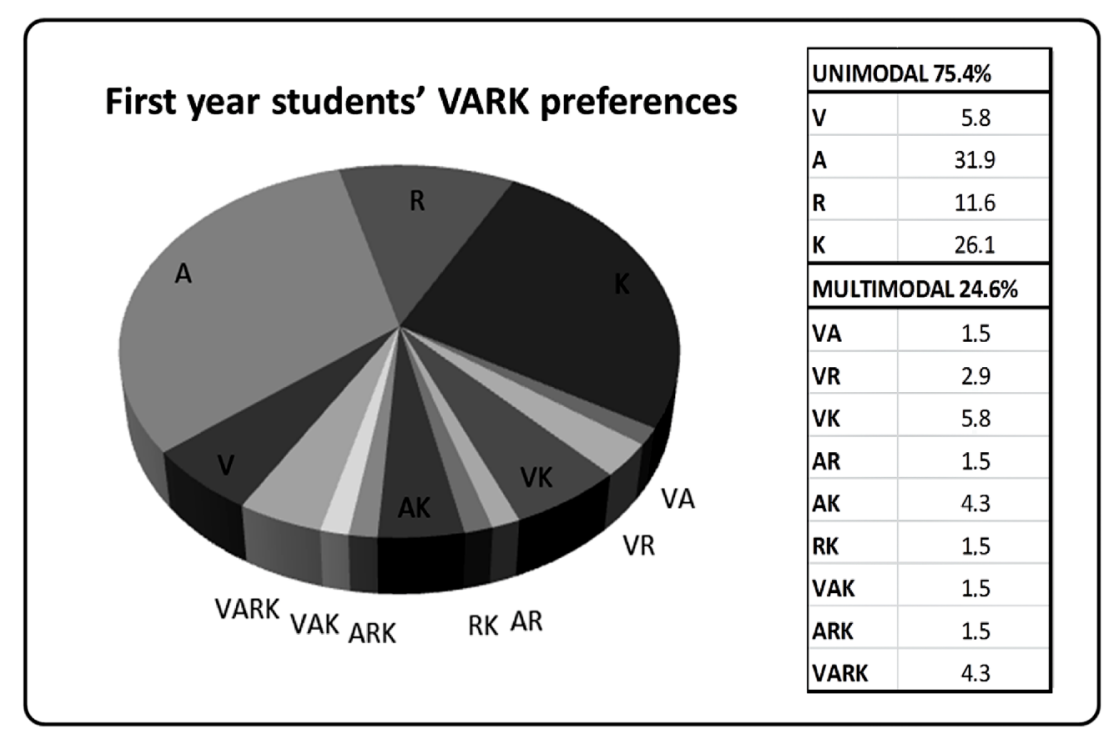

Figure 1. The VARK learning preferences of the first graders have been presented as pie charts; unimodal and multimodal learning preferences are given as groups on the insert table.

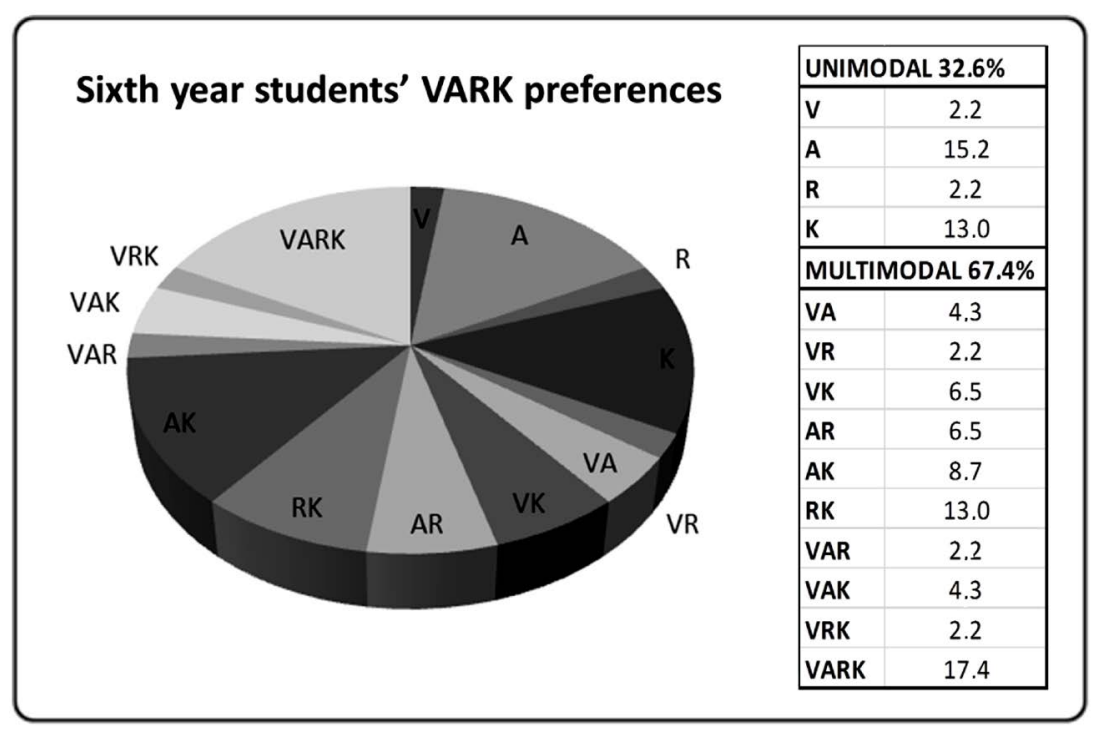

Figure 2. The VARK learning preferences of sixth year students are presented as pie charts; unimodal and multimodal learning preferences are given as groups on the insert table.

ferring a multimodal learning style was 73.3\%; the difference was statistically significant $(p<0.001)$. However, no significant difference was found between the learning preferences of female and male students in the first grade $(p=0.408)$. The rate of male sixth graders preferring a unimodal learning model was $43.8 \%$ and the rate of male sixth graders preferring a multimodal learning model was determined as $56.2 \%$, with a statistically significant difference $(p<0.001)$. No significant correlation was found between the female and male sixth graders in terms of the learning preferences $(p=0.325)$ (Table 1$)$.

\section{Discussion}

In this study, we administered the VARK questionnaire to our first- and sixth-year medical students to determine their preferred modes of learning style differences. Previously a limited number of studies conducted learning 


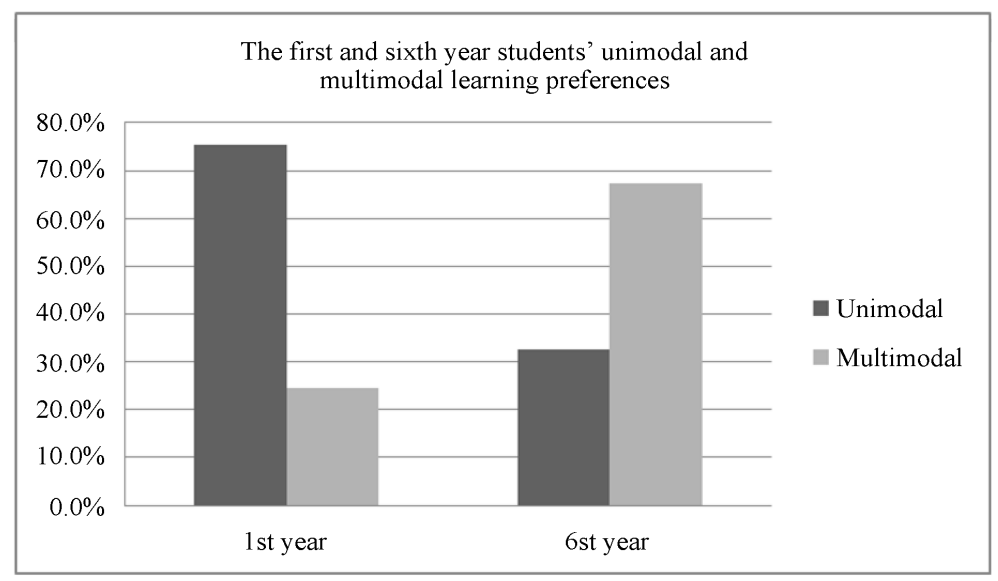

Figure 3. First year students dominantly preferred the unimodal learning style, while the multimodal learning preference was dominant among sixth year's students. The difference between the unimodal and the multimodal learning preferences within the same year and between the different years are statistically significant $(p<0.001)$.

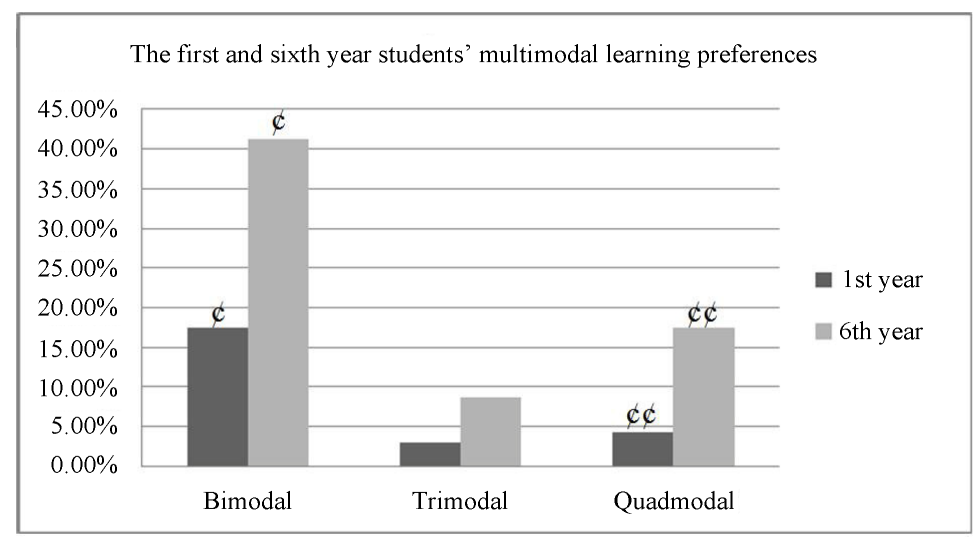

Figure 4. Values related to bimodal, trimodal and quadmodal learning preferences of the first and sixth year students have been presented. While the difference of the trimodal learning style was not significant, the difference between the remaining learning preferences was determined to be significant. $\$$ : $p<0.01, \pitchfork \leftarrow: p<0.05$.

Table 1. Effect of gender on percentage distribution of VARK modalities.

\begin{tabular}{|c|c|c|c|c|}
\hline \multicolumn{5}{|c|}{ Effect of gender on percentage distribution of VARK modalities } \\
\hline \multirow[b]{2}{*}{ VARK mode } & \multicolumn{2}{|c|}{ First year students } & \multicolumn{2}{|c|}{ Sixth years students } \\
\hline & Females & Males & Females & Males \\
\hline Unimodal & $79.5 \%{ }^{*}$ & $70.0 \%^{+}$ & $26.7 \%$ & $43.8 \%{ }^{\mathrm{C}}$ \\
\hline Multimodal & $20.5 \%{ }^{*}$ & $30.0 \%^{+}$ & $73.3 \%{ }^{\#}$ & $56.3 \%^{\mathrm{c}}$ \\
\hline
\end{tabular}

${ }^{*}: p<0.001,{ }^{+}: p<0.001,{ }^{\#}: p<0.001$ and $^{c}: p<0.001$. No difference was found in the learning preferences of female and male students in the same grade.

style differences in medical faculties. Most of these studies focused on the first-year students' style chooses as an important tool for determining suitable and correct education methods. This study focused mainly on the difference in learning styles that occurred during six years of medical education as an example of Baskent University. 
Our findings showed that the preference of learning style changes from unimodal to multimodal in the course of 6 years medical education in Baskent University. The preference for the multimodal learning style was found as $24.6 \%$ and $67.4 \%$ in the first- and sixth-grade students respectively.

Most (75.4\%) of the first-year students preferred a single mode of information presentation (visual, auditory, reading/writing, or kinesthetic). Of the students who preferred a single mode of information presentation, 31.9\% of the students preferred receiving information by speech, which arrives to the learner's ear and is therefore coded as auditory by the questionnaire. In addition to this, only $4.3 \%$ of the students preferred their learning by using all their senses, including touch, hearing, smell, taste, and sight. This group was described as kinesthetic. These students prefer concrete, multisensory experiences in their learning. Only $11.6 \%$ revealed a preference for accessing information from printed words; these students were coded as reading/writing learners because they use reading and writing as their preference for taking in information. Only $5.8 \%$ of the students preferred the visual. These students prefer information to arrive in the form of graphs, charts, and flow diagrams. They are sensitive to different or changing spatial arrangements and can work easily with symbols. These percentages were different at the sixth year as $2.2 \%$ visual, $15.2 \%$ audial, $2.2 \%$ writing and $13 \%$ kinesthetic which comprise a total of $32.6 \%$ unimodal.

Although previous studies have different results, our findings showed that the first-year students of Baskent University have unimodal learning preference and this learning preference changed from unimodal to multimodal as a consequence of six years medical education.

Educational researchers postulate that everyone has a learning style, and if instruction is adapted to accommodate that style, it is anticipated that improved learning will result. In a previous study, educating students after having qualified information about their learning style preferences was found to provide a more successful outcome compared to a blindfold education [12]. For instance, students preferring a multimodal learning model exhibit a more flexible learning approach. However, students preferring a unimodal learning model obtain a favorable result via their dominant preferences only. In this context, educators need to consider these variations among students and implement multiple educational techniques during the teaching process [13]. Hence, awareness on the learning preferences of the students will not only facilitate the learning process of the students, but also simplify the teaching process of the educator [14]. Eventually, both the time and effort consumed for learning and teaching will be decreased.

Lujan and Dicarlo [15] reported that only 36.1\% of the students preferred a single mode of information presentation in the first-year students at Wayne State University School of Medicine. These findings are similar to the findings of Nuzhat A. et al. (2011) [16]. Similar to this finding, another group from Turkey reported the learning styles of the first-year medical students as they have a unimodality preference of $36.1 \%$ and multimodality of $63.9 \%(n=155)$, which were performed at the Department of Medical Education of Erciyes University in February 2006 [17]. These results showed that learning style preferences of first-year students could show difference in the same country. With this approach, the learning preferences of students who have recently entered Medical School will reflect their learning preferences at high school. In the trial performed by Demir R. in 2011 [18] on a total of 525 students in different types of high schools in Turkey (Anadolu High School, Vocational High School for Girls, Science High School, Sports High School), 89\% of the students were observed to prefer the unimodal learning model, with $33.5 \%$ of these participants dominantly preferring the aural learning model [15] [19]. Similarly, most of the first graders in the current study (75.4\%) preferred the unimodal learning model, and the aural learning model was determined as the dominant style among these models (31.9\%) [19]-[22]. Samarakoon L. et al. (2013) [23] have found that the majority (69.9\%) of the first-year students had multimodal learning styles and the majority (67.5\%) of final-year students had multimodal learning styles. Differently, Mon A.A. et al. (2014) [24] have found that the majority of the first-year students had chosen quadmodal learning style preference. Khalid A. et al. (2015) [25] showed that the majority of the first-year students had chosen bimodal learning style preference. Considering the gender and the learning model preferences, we did not find any significant difference between male and female students [19] [26]. Our findings were different from findings of Sarabi-Asiabar et al. (2015) [27].

Determination and recognizing the variations in the learning preferences of students are important for the academicians of faculties. On the other hand, the alterations in the learning styles of students who attend medical faculties after high school are not clear yet. In the current study, the learning models of the first and sixth graders at the Baskent University Medical Faculty were compared to investigate the alterations (if any) at the end of the 6-year medical education. Baskent University Medical Faculty uses an integrated curriculum. Our results 
showed that the preference of unimodal learning style changed to multimodal in six years education period of this faculty. Medical education is a long and complex educational program. Over the course, in addition to professional knowledge, the student must also be adequately furnished with professional skills. Medical students may adjust to the different teaching styles faced in a day or they may opt in and out of alternative strategies, such as being visual/kinestetic in cardiovascular system and reading/writing in psychology etc. To increase the level and quality of education, identification of the learning styles of the students is very important [22] [28].

Gurpinar et al. (2011) [29] also evaluated the relation between curriculum models and learning changes. They found that learning style changed between $2 \mathrm{yr}$ in $46.9 \%$ of the students in the integrated curriculum, $49.3 \%$ of the students in the hybrid curriculum, and $56.4 \%$ of the students in the problem-based learning curriculum. The result of the study showed that the curriculum models did not have a significant effect on learning styles over a period of 2 years. They suggested that the learning styles of medical students may change over time and long-term follow-up studies in larger groups are needed to clarify this relation.

Although by matching their needs they can easily learn conceptual material provided, it arrives with suitable analogies or real-life examples. Most of the students in the sixth year, however, preferred multiple modes of information presentation. These students had a balanced set of preferences, which means that they prefer information to arrive in a variety of modes.

Our results showed that the first-year students of Baskent University have unimodal learning preference and this preference changed to multimodal during the education period of six years. No significant correlation was found between the gender and the learning model preferences. Knowing the students preferred modes can provide a focus for developing strategies that are tailored for individuals. In doing so, this helps to overcome the predisposition of many educators to treat all students in a similar way. Also applying this type of questionnaires can motivate teachers to move from their preferred mode(s) to using others. In doing so, they can reach more students because of the better match between teacher and learner styles.

\section{References}

[1] Felder, R.M. (1996) Matters of Style. ASEE Prism, 6, 18-23.

[2] Fleming, N.D. and Mills, C. (1992) Not Another Inventory, Rather a Catalyst for Reflection. To Improve the Academy, 11, 137.

[3] Davis, B.G. (2003) Tools for Teaching. Jossey-Bass Publishers, San Francisco.

[4] Marcy, V. (2001) Adult Learning Styles: How the VARK Learning Style Inventory Can Be Used to Improve Student Learning. Journal of the Association of Physician Assistant Programs, 12. http://vark-learn.com/wp-content/uploads/2014/08/VanessaMarcy.pdf http://dx.doi.org/10.1097/01367895-200107000-00007

[5] Neel, J.A. and Grindem, C.B. (2010) Learning-Style Profiles of 150 Veterinary Medical Students. Journal of Veterinary Medical Education, 37, 347-352. http://dx.doi.org/10.3138/jvme.37.4.347

[6] Santhamma, J., Angelo, D.A. and Theda, T. (2011) Learning Preferences of First Year Nursing and Midwifery Students: Utilising VARK. Nurse Education Today, 31, 417-423. http://dx.doi.org/10.1016/j.nedt.2010.08.008

[7] Halbert, C., Kriebel, R., Cuzzolino, R., Coughlin, P. and Fresa-Dillon, K. (2011) Self-Assessed Learning Style Correlates to Use of Supplemental Learning Materials in an Online Course Management System. Medical Teacher, 33, 331333. http://dx.doi.org/10.3109/0142159X.2011.542209

[8] Nilsson, M., Östergren, J., Fors, U., Rickenlund, A., Jorfeldt, L., Caidahl, K. and Bolinder, G. (2012) Does Individual Learning Styles Influence the Choice to a Web-Based ECG Learning Programme in a Blended Learning Setting? BMC Medical Education, 12, 1-8. http://dx.doi.org/10.1186/1472-6920-12-5

[9] Caulley, L., Wadey, V. and Freeman, R. (2012) Learning Styles of First-Year Orthopedic Surgical Residents at 1 Accredited Institution. Journal of Surgical Education, 69, 196-200. http://dx.doi.org/10.1016/j.jsurg.2011.09.002

[10] Horton, D.M., Steven, D., Wiederman, S.D. and Saint, D.A. (2012) Assessment Outcome Is Weakly Correlated with Lecture Attendance: Influence of Learning Style and Use of Alternative Materials. Advances in Physiology Education, 36, 108-115. http://dx.doi.org/10.1152/advan.00111.2011

[11] Fleming, N. (2012) VARK: A Guide to Learning Styles.

[12] Christou, N. and Dinov, I.D. (2010) A Study of Students’ Learning Styles, Discipline Attitudes and Knowledge Acquisition in Technology-Enhanced Probability and Statistics Education. Journal of Online Learning and Teaching, 6, 143. 
[13] Alkhasawneh, I.M., Mrayyan, M.T., Docherty, C., Alashram, S. and Yousef, H.Y. (2008) Problem-Based Learning (PBL): Assessing Students' Learning Preferences Using VARK. Nurse Education Today, 28, 572-579. http://dx.doi.org/10.1016/j.nedt.2007.09.012

[14] Prithishkumar, I.J. and Michael, S.A. (2014) Understanding Your Student: Using the VARK Model. Journal of Postgraduate Medicine, 60, 183-186. http://dx.doi.org/10.4103/0022-3859.132337

[15] Lujan, H.L. and Di Carlo, S.E. (2006) First-Year Medical Students Prefer Multiple Learning Styles. Advances in Physiology Education, 30, 13-16. http://dx.doi.org/10.1152/advan.00045.2005

[16] Nuzhat, A., Salem, R.O., Quadri, M.S.A. and Al-Hamdan, N. (2011) Learning Style Preferences of Medical Students: A Single-Institute Experience from Saudi Arabia. International Journal of Medical Education, 2, 70-73. http://dx.doi.org/10.5116/ijme.4e36.d31c

[17] Baykan, Z. and Nacar, M. (2007) Learning Styles of First-Year Medical Students Attending Erciyes University in Kayseri, Turkey. Advances in Physiology Education, 31, 158-160. http://dx.doi.org/10.1152/advan.00043.2006

[18] Demir, R. (2011) Lise türlerine göre öğrencilerin öğrenme stilleri ve sağ sol beyin profillerinin incelenmesi. III. Ulusal Öğretmenim Sempozyumu. Sözlü bildiri, Adana.

[19] Urval, R.P., Kamath, A., Ullal, S., Shenoy, A.K., Shenoy, N. and Udupa, L.A. (2014) Assessment of Learning Styles of Undergraduate Medical Students Using the VARK Questionnaire and the Influence of Sex and Academic Performance. Advances in Physiology Education, 38, 216-220. http://dx.doi.org/10.1152/advan.00024.2014

[20] Liew, S.-C., Sidhu, J. and Barua, A. (2015) The Relationship between Learning Preferences (Styles and Approaches) and Learning Outcomes among Pre-Clinical Undergraduate Medical Students. BMC Medical Education, 15, 44. http://dx.doi.org/10.1186/s12909-015-0327-0

[21] Anita, K., Saee, D. and Jayashree, J. (2014) Evaluation of Learning Styles of Dental Students: A Preliminary Investigation. JETHS, 1, 34-38.

[22] Peyman, H., Sadeghifar, J., Khajavikhan, J., Yasemi, M., Rasool, M., Yaghoubi, Y.M., Nahal, M.M.H. and Karim, H. (2014) Using VARK Approach for Assessing Preferred Learning Styles of First Year Medical Sciences Students: A Survey from Iran. Journal of Clinical and Diagnostic Research, 8, GC01-GC04.

[23] Samarakoon, L., Fernando, T. and Rodrigo, C. (2013) Learning Styles and Approaches to Learning among Medical Undergraduates and Postgraduates. BMC Medical Education, 13, 42. http://dx.doi.org/10.1186/1472-6920-13-42

[24] Mon, A.A., Fatini, A., Ye, C.W., Barakat, M.A., Jen, P.L. and Lin, T.K. (2014) Learning Style Preferences among Pre-Clinical Medical Students. Journal of Medical and Allied Sciences, 4, 22-27.

[25] Khalid, A., Rahim, K., Bashir, Z. and Hanif, A. (2015) Learning Style Preferences among Students of Medical and Dental Colleges. Advances in Health Professions Education, 1, 13-17.

[26] Javadinia, A., Sharifzade, G., Abedini, M., Khalesi, M. and Erfaniyan, M. (2012) Learning Styles of Medical Students in Birjand University of Medical Sciences According to VARK Model. Iranian Journal of Medical Education, 11, 584-589.

[27] Sarabi-Asiabar, A., Jafari, M., Sadeghifar, J., Tofighi, S., Zaboli, R., Peyman, H., Salimi, M. and Shams, L. (2015) The Relationship between Learning Style Preferences and Gender, Educational Major and Status in First Year Medical Students: A Survey Study From Iran. Iranian Red Crescent Medical Journal, 17, Article ID: e18250.

[28] Daud, S., Kashif, R. and Chaudhry, A.M. (2014) Learning Styles of Medical Students. South East Asian Journal of Medical Education, 8, 40-46.

[29] Gurpinar, E., Bati, H. and Tetik, C. (2011) Learning Styles of Medical Students Change in Relation to Time. Advances in Physiology Education, 35, 307-311. http://dx.doi.org/10.1152/advan.00047.2011 